\title{
A MEDIAÇÃO DA INFORMAÇÃO NOS ARQUIVOS PERMANENTES: SERVIÇOS DE REFERÊNCIA ARQUIVÍSTICA NO AMBIENTE DIGITAL
}

\author{
LA MEDIACIÓN DE LA INFORMACIÓN EN LOS ARCHIVOS \\ PERMANENTES: SERVICIOS DE REFERENCIA ARCHIVÍSTICA EN \\ EL AMBIENTE DIGITAL
}

\begin{abstract}
Fernando Alves Gama - feralgam@bol.com.br Mestrando em Ciência da Informação pela Universidade Estadual Paulista Júlio de Mesquita Filho.

Edberto Ferneda - edbertof@terra.com.br Doutor em Ciências da Comunicação pela Universidade de São Paulo Professor Assistente da Universidade Estadual Paulista Júlio de Mesquita Filho Brasil
\end{abstract}

\begin{abstract}
Resumo
A Ciência da Informação tem por objeto o estudo das propriedades gerais da informação e a análise de seus processos de construção, comunicação e uso. Dentre os tipos informacionais encontra-se a informação orgânica, que é registrada em documentos de arquivo. Os usuários dessa informação podem ser divididos em dois grupos distintos pelo uso na fase corrente, por administradores, e na fase de guarda permanente, por historiadores e cidadãos. Uma vez definido o comportamento informacional de cada um dos grupos, a discussão é direcionada para a mediação da informação nos arquivos permanentes; em que é apresentada a interação de usuários e profissionais da informação, por meio do serviço de referência, visando à satisfação de necessidades informacionais. Nesse contexto são apresentados os padrões arquivísticos de descrição com os instrumentos de pesquisa enquanto ferramentas do serviço de referência nos arquivos permanentes. O presente texto versa, ainda, acerca das tecnologias da informação e das novas possibilidades de promoção da informação orgânica registrada em arquivos permanentes no ambiente digital, mediante contribuições oriundas da arquitetura da informação de web sites e da conversão dos padrões arquivísticos de descrição.
\end{abstract}

\section{Palavras-chave}

Arquivos permanentes. Serviço de referência. Mediação da informação. Comportamento informacional. Descrição arquivística. Linguagens de marcação. Arquitetura da Informação. 


\section{INTRODUÇÃO}

A Ciência da Informação $(\mathrm{Cl})$ é caracterizada como área que analisa as propriedades, o comportamento e fluxo de informações, bem como seu processamento a fim de aperfeiçoar o seu uso e acessibilidade.

Um dos enfoques da $\mathrm{Cl}$ é a informação orgânica, ou arquivística, a qual é produzida por um indivíduo ou uma instituição no exercício de suas funções e atividades administrativas. Essa informação encontra-se registrada em documentos de arquivo, que tem um ciclo de vida que pode ser dividido em três fases integradas: corrente, intermediária e permanente.

Os usuários da informação orgânica apresentam necessidades informacionais distintas durante as fases do ciclo documental, tornando-se muito complexas na fase de guarda permanente. Isso ocorre porque na fase corrente os documentos são gerados para atender os interesses do produtor, enquanto na fase permanente o uso poderá ser direcionado a outras finalidades.

O presente trabalho tem por objetivo apresentar as características inerentes aos registros da informação orgânica, bem como o comportamento informacional dos usuários nas três fases do ciclo de vida documental.

Investiga também o processo de referência em arquivos permanentes e analisa as contribuições trazidas pela Arquitetura da Informação e os padrões de metadados para a mediação da informação orgânica em arquivos permanentes.

\section{A INFORMAÇÃO ORGÂNICA}

Segundo Le Coadic (2004, p.25) a Ciência da Informação tem por objeto "o estudo das propriedades gerais da informação (natureza, gênese, efeitos) e a análise de seus processos de construção, comunicação e uso." Informação essa caracterizada como "um conhecimento inscrito (registrado) em forma escrita (impressa ou digital), oral ou audiovisual em um suporte" (2004, p. 5). Dentre os tipos de informação estudados na Ciência da Informação encontra-se a informação arquivística, ou orgânica.

A informação orgânica é produzida por entidades, ou seja, indivíduos e instituições no exercício de funções e atividades por meio do registro em documentos de arquivo. Os registros são gerados, portanto, durante uma sequência de trâmites administrativos que compõem as transações das atividades que, por sua vez, permitem a execução de funções administrativas. Esse processo é denominado fluxo documental.

Buckland (1991) afirma que a informação registrada é dotada de evidência e permite representação de eventos. A informação orgânica traz evidência para as atividades, ou seja, eventos executados por indivíduos ou instituições permitindo ao usuário conhecer os procedimentos administrativos e seus resultados, bem como interagir com os mesmos.

As finalidades de apropriação da informação orgânica são alteradas no decorrer do tempo por comportamentos informacionais distintos. Por este motivo os documentos de arquivo são submetidos a um ciclo de vida documental, em 
três fases integradas, onde são dotados de valor primário e, posteriormente, poderão adquirir valor secundário.

Durante a vigência do valor primário os documentos são utilizados nas finalidades para as quais foram produzidos; o que envolve o suprimento das demandas institucionais no cumprimento de obrigações administrativas, fiscais e legais. Já na fase de valor secundário os documentos são utilizados em desígnios diferentes daqueles para os quais foram produzidos; o que diz respeito à comprovação de direitos adquiridos, desenvolvimento de pesquisas científicas ou ainda aquisição de conhecimento cultural.

As fases do ciclo de vida são três: Corrente, Intermediária e Permanente. 0 acervo documental é trabalhado em cada uma delas de modo a proporcionar adequada apropriação da informação pelos usuários (ROUSSEAU; COUTURE, 1998, p.111-123; SCHELLENBERG, 2006, p.179-226).

$\mathrm{Na}$ fase corrente, os documentos recém criados são consultados constantemente e, por este motivo, são mantidos juntos aos produtores. Isso ocorre porque a informação está agregada de valor primário que, por sua vez, serve diretamente aos interesses das atividades dos órgãos da organização. A informação orgânica nesse primeiro momento é consultada como evidencia da execução de processos e transações administrativas.

A fase intermediária caracteriza-se por baixos índices de consultas ao acervo por parte das entidades produtoras. Por esse motivo serão mais bem gerenciados em arquivos centralizados e distantes dos produtores. Durante esse estágio, os documentos aguardarão a expiração do valor primário que ocorrerá com o término da vigência dos prazos de guarda.

Ao término do prazo de vigência, os documentos que trazem informações referentes aos órgãos produtores relativas à organização, funções, diretrizes, decisões, normas, operações e outras atividades institucionais como evidência ou ainda que contenham informações referentes a pessoas, fenômenos ou coisas, caracterizando o valor informativo, deverão ser enviados à guarda permanente. (SCHELLENBERG, 2006, p.181-182)

$\mathrm{Na}$ fase de guarda permanente os documentos serão recolhidos aos fundos de arquivo onde serão guardados por tempo indeterminado. Belloto (2006, p. 129-130) afirma que os fundos abrangem documentos produzidos por uma entidade, seja ela pessoa física ou jurídica, necessários à sua criação, seu funcionamento e ao exercício de atividades que justifiquem sua existência. Tais documentos mantêm relação orgânica entre si, constituindo-se em uma unidade distinta. Por essa razão os componentes de um acervo não poderão ser separados ou misturados a outros fundos.

Os fundos são organizados por meio da sistemática de arranjo. Pautandose nas relações e hierarquias existentes entre as funções e as atividades, os fundos são subdivididos em grupos documentais, que por sua vez serão divididos em séries, sendo as séries constituídas de peças documentais. Tais subdivisões permitem filtrar e acessar informações específicas. Por esse motivo deverão respeitar à organicidade.

Os documentos de arquivo seguem os seguintes princípios: 
- Proveniência: princípio norteador da arquivologia que garante a identidade do fundo face à entidade produtora. Determina que documentos produzidos por uma entidade não sejam misturados com documentos provenientes de outras origens.

- Organicidade: determina a condição existencial do acervo, devendo ser esse um reflexo das relações administrativas orgânicas. Os arquivos, portanto, refletirão a estrutura, as funções, e as atividades do organismo produtor.

- Unicidade: Determina que os documentos de arquivo apresentem caráter único em seus propósitos e origens no que tange a forma, espécie ou tipo; logo cada uma das tipologias será única em seus efeitos dentro da organicidade.

- Indivisibilidade ou integridade arquivística: determina que os fundos de arquivo devam ser preservados sem dispersão, mutilação, alienação, destruição não autorizada ou acréscimo indevido. Isso ocorre porque os documentos de arquivo estão inter-relacionados de modo que a informação orgânica surja na contextualização do acervo. Os vínculos existentes entre os documentos permitem, portanto, a representação instituída de evidência dos eventos administrativos executados nas atividades institucionais. Por conseguinte os documentos perdem o seu real significado quando estão fora do acervo, haja vista que deixaram de representar a organicidade à qual estavam vinculados (BELLOTO, 2008, p.17-18).

Uma vez definidos a informação orgânica, o documento enquanto suporte, o ciclo de vida documental e os princípios que norteiam a organização da mesma; passa-se a analisar o comportamento informacional dos usuários da informação orgânica durante o ciclo de vida documental.

\section{O COMPORTAMENTO INFORMACIONAL DOS USUÁRIOS DE ARQUIVO NOS ESTÁGIOS DO CICLO DOCUMENTAL}

Por comportamento de busca informacional compreende-se a procura proposital de informação como consequência de uma necessidade que vise à satisfação de um objetivo. Durante a pesquisa o usuário poderá interagir tanto com sistema de informações manuais, como sistemas de informação computacionais (WILSON, 2000, p. 49).

Um acervo documental arquivístico é dotado de recursos informacionais voltados à apropriação da informação orgânica para finalidades diversas.

Em um primeiro momento o comportamento relaciona-se com as necessidades administrativas de indivíduos e instituições, no exercício de suas atribuições. Destaca-se a recuperação por parte da entidade produtora do acervo quer seja pessoa física construindo um arquivo pessoal, ou pessoa jurídica, um grupo de pessoas executando funções em uma corporação. 
Posteriormente, o comportamento informacional de pesquisadores e cidadãos buscará a compreensão das ações executadas na fase administrativa para satisfazer necessidades relacionadas a investigações que visem ao desenvolvimento científico, à comprovação de direitos, ou ainda a aquisição de conhecimentos culturais.

Observa-se, portanto, que a apropriação da informação orgânica é realizada por diferentes usuários e para diferentes finalidades durante o período de ciclo de vida documental. Para melhor compreensão do comportamento informacional, os usuários do acervo arquivístico deverão ser divididos em duas classes, sendo essas vinculadas ao valor primário e secundário.

Temos, então, uma classe que se apropria da informação orgânica nas fases corrente e intermediária, e outra voltada à fase de guarda permanente. Para efeitos desse estudo as classes denominam-se grupo primário e grupo secundário.

Durante a vigência do valor primário a informação orgânica está disponibilizada ao produtor, sendo vedado o acesso ao público. Neste contexto a informação registrada nos documentos de arquivo é utilizada para os fins pelos quais foi produzida. O usuário, especialista em uma determinada área de atuação, está inserido no ambiente de produção e conhece a estrutura funcional onde atua.

O grupo primário, portanto, interage e interfere no contexto de produção documental.

É possível afirmar que o grupo primário é um agente de produção informacional que gera a se apropria da informação orgânica simultaneamente. Por meio dessas incorporações o grupo registra sua atuação nos eventos administrativos. O contexto de produção é dinâmico e a massa documental cresce constantemente.

Embora a produção documental seja dinâmica, os usuários direcionarão o foco de apropriação aos registros relacionados às suas atribuições. A prédisponibilização de informações é, portanto, facilitada nesse período.

A atuação dos usuários do grupo primário, registrada nos documentos de arquivo, é de fundamental importância para se compreender a informação contida no acervo. Os registros arquivísticos deverão, portanto, representar os indivíduos do grupo primário e suas relações funcionais com a entidade produtora para reforçar a integridade do acervo e a evidência dos eventos ali registrados. Resta ainda dizer que todo o contexto de produção documental inerente à fase de valor primário deverá estar representado na documentação arquivística para que seja possível aos usuários do grupo secundário apropriar-se da informação orgânica.

$\mathrm{Na}$ vigência do valor secundário os usuários do grupo primário não mais interagem na produção documental e raramente necessitarão apropriar-se daquela informação orgânica para o exercício de suas atividades vigentes. Nesse momento os eventos que nortearam a execução das atividades administrativas, bem como seus efeitos imediatos, estão encerrados.

A documentação de valor secundário apresenta alto índice de conteúdo informativo e probatório, o que justificará sua guarda permanente. Nesse contexto a informação orgânica será utilizada para fins diferentes daqueles para os quais foi produzida e os usuários do grupo secundário serão o foco da apropriação. 
Belloto (2006, p.230) afirma que

É sobre um tripé que se sustenta a consulta a um acervo de arquivo: o historiador, o administrador e o cidadão. Para 0 primeiro, ali se concentra sua matéria-prima profissional; para o segundo, seu arsenal de provas, testemunhos e informações; para o terceiro, os dados que informam e definem a comunidade em que vive e sua própria atuação nela.

O grupo secundário é constituído, portanto, de pesquisadores, administradores, e cidadãos. Apropria-se da informação orgânica e com ela interage não mais para interferir no andamento administrativo da instituição naquele contexto de produção; mas para obter conhecimento do funcionamento e das implicações trazidas à sociedade, comprovar direitos, atender a fins culturais, etc.

Schellemberg (2006, p.186) apresenta três tipos de utilização para os arquivos permanentes: "a) mostrar a história da organização em causa; b)responder a questões técnicas relativas as suas operações; e c) atender a possíveis necessidades eruditas de informação que esteja incidental ou acidentalmente contidas nos documentos".

Tantas são as finalidades de investigação promovidas que as consultas ao acervo tornar-se-ão muito dinâmicas e até mesmo difíceis de serem previstas, pois um mesmo evento poderá atender a necessidades informacionais distintas. O acervo, por sua vez, tornar-se-á estático uma vez que dentro daquele contexto não mais haverá produção documental.

Os usuários do grupo secundário encontram-se, portanto, fora do contexto de produção documental do acervo de arquivos permanentes e, embora possam se apropriar da informação orgânica e com ela interagir, não exercem interferência direta nos eventos ali registrados, atuando apenas como investigadores dos mesmos. Isso não significa que o grupo secundário mantenha uma atitude passiva frente ao acervo.

Embora não possa interferir diretamente nos eventos nem tampouco possa alterar o teor de informação contida nos documentos, o pesquisador poderá interferir na escolha das fontes ou ainda na interpretação das transações administrativas de modo a conduzir outros indivíduos a redirecionarem seu foco de compreensão.

No que tange o mapeamento de fontes documentais para a pesquisa historiográfica, Garcez (2009, p.16, grifo do autor) afirma que:

O mapeamento, sabem sobejamente os pesquisadores, é o primeiro e dos mais importantes passos de pesquisa historiográfica, quando se procuram identificar, no acervo documental disponível, as fontes principais diretamente afetas ao estudo do objeto temático já definido. Essas fontes principais, por sua vez, constituem o eixo da pesquisa. Elas são previsíveis, indispensáveis e ignorá-las ou omiti-las significa falha metodológica gravíssima, capaz de comprometer a qualidade final do trabalho historiográfico. Da mesma forma que as fontes complementares inicialmente mencionadas, as não arroladas, imprevistas, localizadas por acaso, intuição ou sorte do 
pesquisador freqüentemente acabam por representar uma achega considerável à construção historiográfica, às vezes, também o "elo perdido".

É de grande importância, portanto, o papel exercido pelas fontes documentais à pesquisa historiográfica. $O$ acervo permanente não está voltado, no entanto, somente à pesquisa historiográfica. Pesquisadores de diversas áreas do conhecimento científico poderão apropriar-se da informação orgânica na condução de suas pesquisas.

Cidadãos poderão recorrer a fontes fidedignas de informação orgânica visando à comprovação de direitos que lhe são inerentes. Poderão também adquirir, por meio dos eventos ali registrados, ciência dos eventos que nortearam o desenvolvimento regional do ambiente onde está inserido, ou satisfazer a outras indagações de seu interesse.

Belloto (2006, p.235-237) apresenta, ainda, a apropriação da informação orgânica para finalidades educacionais. Sugere a autora que documentos específicos e generalizados de um acervo poderão ser combinados para instruir alunos do ensino médio e fundamental em aulas de história regional.

Observa-se, portanto, que é por demais complexa a interação do usuário de arquivo permanente com o acervo documental. Nesse contexto, Andrade (2007, p.72) afirma que

Um dos desafios atuais para as instituições que custodiam
parcelas da memória da sociedade, nesse caso as instituições
arquivísticas, é ampliar sua capacidade de atendimento a uma
clientela cada vez mais diversificada de interessados em obter
acesso aos acervos custodiados. Há uma crescente variação nos
perfis de usuários, anteriormente formada quase que
exclusivamente por historiadores. Espera-se que os cidadãos
comuns percebam o arquivo, notadamente o público, como um
local de acesso à informação de interesse pessoal para a
construção da identidade, exercício da cidadania e, até mesmo,
para atender a curiosidades culturais.

O comportamento informacional do grupo secundário é, portanto, complexo já que são muito diversificadas as finalidades que motivam a apropriação da informação.

A organicidade exerce importante papel no atendimento do comportamento informacional dos usuários de arquivo em todo o ciclo documental. $\mathrm{Na}$ fase de valor primário a organicidade do órgão permitirá que a informação orgânica seja disponibilizada em conformidade com o comportamento informacional dos usuários. Na fase de guarda permanente a relação existente entre o grupo de funções e atividades proporcionadas pela organicidade permitirá aos usuários consultarem os acervos de modo dinâmico.

Uma vez analisado o comportamento informacional dos usuários de um acervo arquivístico passa-se a verificar a mediação da informação em arquivos permanentes por meio do processo de referência.

Embora o foco deste trabalho direcione a mediação da informação orgânica na fase permanente, voltada ao grupo secundário, fez-se necessário uma breve 
abordagem do comportamento informacional do grupo primário tendo em vista que a medição somente ocorrerá mediante uma representação eficiente da atuação do usuário primário no acervo.

\section{A MEDIAÇÃO DA INFORMAÇÃO EM ARQUIVOS PERMANENTES POR MEIO DO SERVIÇO DE REFERÊNCIA.}

É necessário, primeiramente, apresentar uma definição para a Mediação da Informação. Almeida Júnior (2009, p.92) conceitua a mediação da informação como

toda ação de interferência - realizada pelo profissional da informação -, direta ou indireta; consciente ou inconsciente; singular ou plural; individual ou coletiva; que propicia a apropriação de informação que satisfaça, plena ou parcialmente, uma necessidade informacional.

Defende o autor que a mediação da informação encontra-se presente em toda a atuação do profissional da informação, desde o armazenamento à disseminação, uma vez que todos os fazeres estão voltados à recuperação de informações que satisfaçam às necessidades de seus usuários.

A mediação poderá, segundo o autor, assumir forma implícita ou forma explícita. A mediação implícita ocorre no momento em que as ações são desenvolvidas sem a presença física imediata dos usuários; enquanto a mediação explícita ocorre nos espaços onde a presença do usuário, quer seja física ou à distância, é inevitável.

No que tange à interferência do profissional no processo de mediação afirma o referido autor (ALMEIDA JÚNIOR, 2009, p.93) que

No conceito de mediação da informação, destaca-se a afirmação de que é ela uma interferência. Em oposição ao pensamento hegemônico que sustenta a imparcialidade e a neutralidade do profissional da informação no exercício de seu trabalho, defendemos a existência da interferência. É ela constante e indissociada do fazer do profissional da informação.

Sugere, portanto, que a interferência deverá ser afirmada ao invés de ser negada a fim de se diminuir o risco e consequências da manipulação. Tal afirmação é de particular importância ao processo de mediação da informação orgânica uma vez que há um grande envolvimento dos profissionais da área da ciência da informação em sua execução.

A interferência exercida pelos profissionais na construção dos instrumentos de pesquisa, se não for explicitada e cuidadosamente trabalhada poderá resultar em fortes obstáculos ao processo de mediação; uma vez que a terminologia utilizada e a forma de representação do acervo documental poderiam impedir o usuário do acesso à informação. 
$\mathrm{Na}$ mediação da informação explícita destacam-se os serviços de referência devido a sua proximidade com os usuários. Grogan (2001, p.7-34) afirma que o serviço de referência proporciona assistência individual e direta a usuários que buscam informações em um determinado acervo. Tais serviços beneficiam tanto os usuários como a instituição mantenedora. Os usuários são beneficiados por encontrarem as informações de que necessitam e a instituição por demonstrar-se eficaz em promover um fluxo eficiente de informação que facilita a busca e acesso da informação pelo usuário.

Figueiredo (1992, p.10) afirma que, historicamente, o serviço de referência teve suas primeiras alusões em fins do sec. XIX e desde então vem se desenvolvendo no campo da biblioteconomia com vistas ao desenvolvimento de processos de recuperação cada vez mais aprimorados, visando ao atendimento de necessidades informacionais cada vez mais complexas. Admite, no entanto, que:

[...] o serviço de referência cumpre o seu objetivo, de forma mais completa, quando é proporcionado a um indivíduo que trabalha num campo que não está familiarizado. Para um especialista que trabalha em seu próprio campo, o bibliotecário de referência não é tão útil, pois, obviamente, o especialista sabe mais que o bibliotecário (FIGUEIREDO, 1992, p.10).

Em um ambiente de arquivo encontrar-se-ão indivíduos que não estão familiarizados com o teor documental e indivíduos especializados em áreas afins. Diferentemente, entretanto, do acervo bibliográfico, o acervo arquivístico é constituído de informações documentais que não estão publicadas em coleções. Dessa forma, por mais especializado que o usuário possa ser o serviço de referência será indispensável para a apropriação.

Outra particularidade inerente à documentação arquivística é que, conforme visto no princípio da indivisibilidade, os documentos deverão ser interpretados em conjunto para que a informação orgânica neles contida possa reconstituir o contexto de produção documental. O papel do profissional da informação em seu contexto deverá estar voltado à compreensão das estruturas da informação orgânica registrada, onde elas existam e auxiliar no processo de estruturação onde não existam.

O processo do serviço de referência, segundo Grogan (2001, p. 50-54) ocorre em uma sequência lógica de oito etapas consecutivas, apresentadas a seguir:

- O problema: o problema pode ser compreendido com uma determinada circunstância que atrai a atenção do usuário para o acervo. Pode ser gerado por uma fonte interna, de origem psicológica ou cognitiva, ou de uma fonte externa, contexto social ou situacional.

- A necessidade de informação: para se lidar com um problema o usuário sente a necessidade de obter informações. A necessidade poderá ser meramente vaga ou mesmo uma curiosidade que motivará o indivíduo a obter uma resposta.

- A questão inicial: O usuário formula uma pergunta e a direciona ao profissional da informação. 
- A questão negociada: uma vez formulada a questão inicial inicia-se o processo de referência. A questão inicial poderá exigir maiores esclarecimentos ou ajustes para se certificar qual seria a necessidade de informação subjacente. A questão é então comparada com a maneira como as informações estão registradas no acervo. A comparação permite a reformulação da questão em conformidade com a terminologia e a estrutura das informações a serem consultadas.

- A estratégia de busca: decide-se como o acervo de informações será consultado e quais de suas partes serão consultadas e em que ordem.

- O processo de busca: o profissional executa a busca no acervo.

- A resposta: uma vez encontrada uma resposta, o profissional a apresenta ao usuário para verificar se esta atende a necessidade informacional do usuário.

- A solução: tendo a resposta atendido às expectativas do usuário o processo dá-se por finalizado.

O processo de referência deverá se ajustar em profundidade aos objetivos do usuário de arquivo; atendendo, portanto, circunstâncias individualizadas de consultas e das diretrizes da instituição de arquivo as quais certamente não se enquadram em padrões pré-estabelecidos. Isso ocorre porque a solução do problema do usuário é o que se busca durante o processo.

A fim de permitir que o processo de referência da informação orgânica fosse executado de forma mais dinâmica na fase de guarda permanente, a arquivologia desenvolveu o processo de descrição documental; sendo pautado na estrutura desenvolvida no arranjo dos fundos. Consiste na produção de instrumentos de pesquisa que possibilitam "a identificação, o rastreamento, a localização e utilização dos dados” (BELLOTO, 2006, p.179).

Para o Conselho Internacional de Arquivos (2003, p.1) o objetivo do processo descritivo consiste em

[...] identificar e explicar o contexto e o conteúdo de documentos de arquivo a fim de promover o acesso aos mesmos. Isto é alcançado pela criação de representações precisas e adequadas e pela organização dessas representações de acordo com modelos predeterminados. Processos relacionados à descrição podem começar na ou antes da produção dos documentos e continuam durante sua vida. Esses processos permitem instituir controles intelectuais necessários para tornar confiáveis, autênticas, significativas e acessíveis descrições que serão mantidas ao longo do tempo.

O processo descritivo permite, portanto, a construção de instrumentos que auxiliem os profissionais da informação e os usuários durante o processo de referência.

Visando a padronização da elaboração dos instrumentos de pesquisa, o Conselho Internacional de Arquivos (CIA) lançou um padrão de diretrizes gerais 
para a elaboração de instrumentos de pesquisa denominado International Standard Archival Description (General) (ISAD G).

A ISAD (G) permite que a descrição seja executada em níveis que vão do geral, fundo de arquivo, ao particular, item documental. Cada um dos níveis de arranjo, portanto, correspondem a um nível de descrição (BELLOTO, 2006, p.182).

A ISAD (G) apresenta os seguintes campos

1. Área de identificação: identificação da unidade de descrição;

2. Área de contextualização: origem e custódia da unidade de descrição;

3. Área de conteúdo e estrutura: assunto e organização da unidade de descrição;

4. Área de condições de acesso e de uso: acessibilidade da unidade de descrição;

5. Área de fontes relacionadas: outras fontes que apresentem relacionamento importante com a unidade de descrição;

6. Área de notas: qualquer outra informação que não possa ser incluída em nenhuma das outras áreas;

7. Área de controle da descrição: como, quando e por quem a descrição arquivística foi elaborada. (CONSELHO INTERNACIONAL DE ARQUIVOS, 2003)

Uma vez elaborada a $\operatorname{ISAD}(\mathrm{G})$ surgiu a necessidade de se descrever o contexto de produção documental, mais precisamente, os indivíduos que geraram essa documentação no período de valor primário. O CIA então desenvolveu a norma International Standard Archival Authority Record for Corporate Bodies, Personsand Families (ISAAR (CPF)). A ISAAR apresenta os seguintes campos de descrição:

1. ÁREA DE IDENTIFICAÇÃO: Define o tipo, o nome da entidade

2. ÁREA DE DESCRIÇÃO: descrever a história, papéis, contexto e atividades da entidade coletiva, pessoa e família

3. ÁREA DE RELACIONAMENTOS: descrever relacionamentos com outras entidades coletivas, pessoas e famílias

4. ÁREA DE CONTROLE: define o código, a instituição de custódia, idioma dentre outros aspectos (CONSELHO INTERNACIONAL DE ARQUIVOS, 2004).

Embasado nos padrões do CIA, o Conselho Nacional de Arquivos (CONARQ) elaborou a Norma Brasileira de Descrição Arquivística (NOBRADE) que tem por objetivo adaptar a normas ISAD (G) e ISAAR (CPF) à realidade brasileira, com ênfase na descrição automatizada. A NOBRADE é muito semelhante ao padrão ISAD (G). Apresenta, no entanto, uma oitava área intitulada: Área de pontos de acesso e indexação de assuntos (CONSELHO NACIONAL DE ARQUIVOS, 2006).

Uma vez apresentadas as normas que norteiam os instrumentos de pesquisa delas oriundos. Elaborados no padrão $\operatorname{ISAD}(G)$, são os instrumentos ferramentas desenvolvidas para promover a representação da informação orgânica nos mais diversificados níveis hierárquicos. São, portanto, fontes de 
consulta muito relevantes para o serviço de referência. São três os principais tipos de instrumentos de pesquisa, a saber: o guia, o inventário e o catálogo.

O Guia é o instrumento mais abrangente pois fornece uma descrição sumária do arquivo e de seus fundos tais como datas dos documentos mais antigos, se o acervo apresenta caráter estritamente histórico, a importância do fundo em uma determinada área ou assunto (BELLOTO, 2006, p. 194).

O Inventário descreve conjuntos documentais ou partes de um fundo, podendo contemplar um fundo inteiro, um grupo ou parte dele, uma série ou um conjunto delas, ou mesmo parte de uma série (BELLOTO, 2006, 197-199).

O Catálogo por sua vez descreve cada uma das peças documentais de uma ou mais séries.

Os instrumentos de pesquisa, portanto, em conformidade com as normas nacionais e internacionais de descrição arquivística, auxiliarão os serviços de referência no que tange a promoção da mediação da informação nos arquivos permanentes.

Uma vez estudado o processo de mediação da informação por meio do serviço de referência em arquivos permanentes, passa-se a analisar as contribuições trazidas pelas Tecnologias da Informação (TI).

\section{A MEDIAÇÃO DA INFORMAÇÃO ORGÂNICA PERMANENTE EM AMBIENTES DIGITAIS.}

O advento da Tecnologia da Informação (TI) trouxe novas possibilidades para se promover a apropriação da informação orgânica em arquivos permanentes; permitindo que pesquisadores e cidadãos se apropriem do conteúdo informacional existente nos instrumentos de pesquisa sem que haja a necessidade de se deslocarem à instituição de custódia.

No que diz respeito ao desenvolvimento de web sites para instituições arquivísticas o CONARQ $(2000$, p.4) comenta que:

O website de uma instituição arquivística deve ser visto como um instrumento de prestação de serviços - dinâmico e atualizável - e não simplesmente como a reprodução de um folder institucional. Trata-se, na verdade, de um espaço virtual de comunicação com os diferentes tipos de usuários da instituição a ser gerenciado como parte da política de informação da instituição. Dado o potencial e as características da Internet, este espaço, além de redefinir as formas de relacionamento com os usuários tradicionais, poderá atrair outros que, por várias razões, difícil ou raramente procurariam o Arquivo como realidade física.

Visando contribuir para o desenvolvimento de web sites arquivísticos o presente estudo abordará, de forma sumária, alguns elementos que podem trazer grande contribuição para o serviço de referência de acervos arquivísticos na web, a saber: arquitetura da informação em web sites, e o uso de Docment Type 
Definition (DTD) como padrão de metadados para a elaboração de instrumentos de pesquisa.

Morville e Rosenfeld (2006, p.4) apresentam quatro definições para Arquitetura da Informação (Al). A saber:

- O design estrutural de ambientes de informações compartilhadas;

- A combinação de sistemas de organização, rotulação, busca e navegação em sistemas de web sites e intranets;

- A ciência e a arte de se formular experiências e produtos informacionais que permitam a usabilidade $\mathrm{e}$ encontrabilidade; $\mathrm{e}$

- Uma disciplina emergente e comunidade de práticas focadas em conduzir princípios de arquitetura e design ao ambiente digital.

A arquitetura da informação permite estruturar a construção de ambientes informacionais direcionados às necessidades dos usuários possibilitando-lhes recuperar informações. A aplicação da Al na elaboração de websites arquivísticos é fundamental para que os mesmos possam atender seus diferentes grupos de usuários com necessidades informacionais distintas.

Para lograr êxito neste feito os arquitetos executam procedimentos para estruturar organizar e rotular a informação disponibilizada no site, visando à recuperação por parte do usuário e ao gerenciamento por parte da instituição de custódia (MORVILLE; ROSENFELD, 2006).

Estruturar diz respeito aos níveis de granularidade de informação que serão trabalhados no web site, ou seja, como a informação poderia ser categorizada. Por granularidade compreende-se o nível de detalhamento que receberão os grupos informacionais. No que diz respeito à informação orgânica a estrutura estaria relacionada à subdivisão dos fundos até chegar ao item documental.

Uma vez analisada a estrutura executa-se a organização, onde os elementos da estrutura são agrupados em categorias distintas e gerenciáveis entre si. Temos, portanto, a organização dos níveis de descrição do acervo, a saber: fundo, grupos, séries e subséries, item documental.

Quando as categorias já se encontram estruturadas e organizadas desenvolve-se o processo de rotulação. Por meio dos rótulos denominar-se-ão os recursos informacionais existentes em cada uma das categorias. A terminologia escolhida para a construção dos rótulos exercerá a recuperação da informação disponibilizada na web, pois os rótulos permitirão a interação do usuário com o ambiente. Uma terminologia inapropriada na rotulação, portanto, inviabilizará os objetivos do site. Os nomes dados aos grupos e séries documentais poderão servir como elementos de rotulação.

Uma vez definidos as categorias de informação juntamente com os rótulos que as descrevem, desenvolvem-se os sistemas de navegação, onde é projetada a interface por onde o usuário interagirá, e se define como serão apresentadas as diferentes hierarquias informacionais aos usuários. 
Os procedimentos mencionados são realizados com embasamento em uma investigação pormenorizada pautada no comportamento informacional dos usuários, o contexto de uso e o conteúdo. A interação desses três elementos indicará ao arquiteto quais elementos serão mais bem utilizados na elaboração do site.

A arquitetura da informação é, portanto, elemento indispensável na elaboração de sites arquivísticos que visem à mediação da informação orgânica registrada em arquivos permanentes.

Uma vez estando o acervo documental descrito em conformidade com os padrões de descrição torna-se necessário convertê-los em recursos de metadados que possam ser compreendidos também pelas máquinas, permitindo que as mesmas interajam no processo de mediação.

A linguagem de marcação Extensible Markup Language (XML) destaca-se nos recursos oferecidos. Ferneda (2003, p.105) comenta que "a linguagem XML possibilita discriminar cada uma das características e apresentar 0 dado relacionado à característica." Essa linguagem não apresenta predefinição de marcas, permitindo ao desenvolvedor rotular os dados da forma que julgar necessário. O uso da XML é, portanto, recomendado em padrões de metadados para a representação da informação orgânica, a fim de possibilitar a mediação.

Ferneda (2003, p.105) comenta ainda que "a especificação de um esquema, embora opcional, é importante para manter a consistência de um documento XML, permitindo verificar a validade frente ao esquema definido". Surge nesse contexto o uso da DTD que permitirá a validação dos registros XML frente aos padrões de metadados declarados no esquema.

Sobre o uso de uma DTD em documentação arquivística, Andrade (2007, p.87) afirma que:

A declaração formal das etiquetas, das estruturas e das relações permite que, por exemplo, diferentes arquivistas em distintas instituições codifiquem seus instrumentos de pesquisa de forma que o produto seja um documento XML semelhante em estrutura. Assim, caso seja necessário, seria possível a conectividade entre os sistemas de informação de suas respectivas instituições.

Visando a construção padronizada em instrumentos de pesquisa em XML desenvolveu-se em DTD o padrão de metadados Encoded Archival Description, ou seja, descrição arquivística codificada (EAD) voltada para a norma ISAD (G); e o padrão Encoded Archival Description, ou seja, contexto arquivístico codificado (EAC) voltado à norma ISAAR (CPF).

Segundo Andrade (2007, p.88) os critérios de desenvolvimento tinham por objetivo:

1 Representar instrumentos arquivísticos de acesso, de forma extensiva e inter-relacionada; 2 Preservar as relações hierárquicas existentes entre os níveis de descrição; 3 Permitir que uma informação descritiva fosse herdada de um nível hierárquico ao outro; 4 Permitir que uma estrutura informacional pudesse ser movida dentro de uma hierarquia; 5 Suportar recuperação e indexação de elementos específicos. 
O desenvolvimento da EAD iniciou-se em 1993 na biblioteca da Universidade da Califórnia sob a liderança de Daniel Pitti. A primeira versão da DTD foi lançada no ano de 1998, e posteriormente lançou-se outra versão em 2002, vigente até o presente momento (THURMAN, 2005; ANDRADE, 2007).

Uma vez lançada a primeira versão da EAD, surgiu a necessidade de se desenvolver um padrão de metadados que permitisse a representação os campos pertencentes à norma ISAAR (CPF) referente à atuação dos produtores da documentação. Com este objetivo um grupo internacional de arquivistas e cientistas da informação se reuniu em 2001 na universidade de Toronto e desenvolveu o padrão de metadados EAC (THURMAN, 2005, p.196).

Os padrões de metadados EAD e EAC definem campos para representação da informação orgânica nos moldes estabelecidos pelos padrões de descrição ISAD e ISAAR, possibilitando a elaboração de instrumentos de pesquisa em XML rigorosamente padronizado, o que permite a interoperabilidade, ou seja, a troca de dados entre sistemas computacionais de diferentes instituições arquivísticas. Passa-se a analisar cada um dos padrões de metadados.

O padrão de metadados EAD define um conjunto de etiquetas e regras estruturais para a codificação de instrumentos de pesquisa. Cada elemento é nomeado em etiquetas legíveis. Por exemplo, a etiqueta <eadheader $>$ pode ser interpretada como cabeçalho.

Os elementos do padrão poderão ser delineados por meio de atributos especificadores. Por exemplo: O elemento descrição arquivística <archdesc>, descrição arquivística, poderá ser especificado com o atributo [level], nível hierárquico, para o valor fundo, sendo representado <archdesc level= "fundo">. Isto significa que o nível hierárquico descrito é um fundo; mas o valor ainda poderia ser series, documento, ou outro valor necessário (THURMAN, 2005 p.188).

Uma vez apresentada a estrutura dos elementos passemos a estudar os elementos presentes na DTD EAD.

A DTD é a aberta com o cabeçalho <ead> e dentro deste estão os três principais elementos da norma, a saber:

- <eadheader> - permite informações referentes a ao processo de elaboração e uso do instrumento de pesquisa;

- <frontmatter> - permite inserir informações prefaciais do plano de metadados

- <archdesc> - permite inserir informações referentes à descrição do acervo.

O archdesc é o elemento que conterá os atributos de representação do nível de informação orgânica. $O$ archdesc traz consigo os seguintes elementos:

\begin{tabular}{|l|l|l|}
\hline Tags & Nome dos Elementos & Conteúdo Informacional \\
\hline$<$ did $>$ & Descriptive Identification & $\begin{array}{l}\text { Elemento de identificação essencial, incluindo } \\
\text { origem, descrição física e localização. }\end{array}$ \\
\hline$<$ accessrestrict $>$ & $\begin{array}{l}\text { Conditions Governing } \\
\text { Access }\end{array}$ & Disponibilidade de acesso ao material. \\
\hline$<$ accruals $>$ & Accruals & Adições antecipadas no material. \\
\hline
\end{tabular}


Fonte imediata de material.

\section{Quadro 1 Elementos da tag Achival Description - <archdesc> elements \\ Fonte: THURMAN, 2005 p.190. Tradução Livre}

\begin{tabular}{|c|c|c|}
\hline Tags & Nome dos Elementos & Conteúdo Informacional \\
\hline <altformavail> & Alternative Form Available & Copias do material em formatos adicionais. \\
\hline <appraisal> & Appraisal Information & $\begin{array}{l}\text { Processos de determinação do valor } \\
\text { arquivístico do material }\end{array}$ \\
\hline <arrangement> & Arrangement & Ordenação e estrutura interna do material. \\
\hline$<$ bibliography> & Bibliography & $\begin{array}{l}\text { Citações de trabalhos } \\
\text { material. }\end{array}$ \\
\hline <bioghist> & Biography or History & $\begin{array}{l}\text { Produtor (indivíduo, família. ou corpo } \\
\text { coorporativo) do material, para prover } \\
\text { contexto. }\end{array}$ \\
\hline <controlaccess $>$ & $\begin{array}{l}\text { Controlled } \\
\text { Headings }\end{array}$ & $\begin{array}{l}\text { Nomes de cabeçalho pessoal, coorporativo, } \\
\text { geográfico e cabeçalhos de assunto. }\end{array}$ \\
\hline <custodhist> & Custodial History & $\begin{array}{l}\text { Cadeia de propriedade intelectual e posse } \\
\text { física. }\end{array}$ \\
\hline$<$ descgrp $>$ & Description Group & $\begin{array}{l}\text { [elemento genérico para agrupar outros } \\
\text { elementos ] }\end{array}$ \\
\hline$<$ fileplan> & File Plan & $\begin{array}{l}\text { Plano de classificação utilizado pelos } \\
\text { produtores do material. }\end{array}$ \\
\hline$<$ <index> & Index & $\begin{array}{l}\text { Listas de palavras chaves, assuntos, e } \\
\text { entidade - poderá incluir links }\end{array}$ \\
\hline$<$ odd $>$ & Other Descriptive Data & $\begin{array}{l}\text { [recurso para adicionar dados que não se } \\
\text { enquadraram em outros elementos ] }\end{array}$ \\
\hline <originalsloc> & Location of Originals & $\begin{array}{l}\text { Existência, localização e disponibilidade dos } \\
\text { originais quando os materiais descritos são } \\
\text { cópias. }\end{array}$ \\
\hline <otherfindingaid> & Other Finding Aid & Guias alternativos para o material \\
\hline$<$ phystech $>$ & $\begin{array}{l}\text { Physical Characteristics } \\
\text { and Technical } \\
\text { Requirements }\end{array}$ & $\begin{array}{l}\text { Necessidades físicas ou técnicas que afetem o } \\
\text { armazenamento, preservação e uso do } \\
\text { material. }\end{array}$ \\
\hline$<$ prefercite $>$ & Preferred Citation & Versa sobre material de citação \\
\hline$<$ processinfo $>$ & Processing In formation & Preparação do material para uso em pesquisa \\
\hline$<$ <relatedmaterial $>$ & Related Material & $\begin{array}{l}\text { Material não incluso na coleção que pode ser } \\
\text { de interesse do pesquisador. }\end{array}$ \\
\hline <scopecontent> & Scope and Content & Alcance e cobertura tópica do material \\
\hline $\begin{array}{l}<\text { separatedmaterial } \\
>\end{array}$ & Separated Material & $\begin{array}{l}\text { Materiais de origens comuns que estejam } \\
\text { fisicamente separados. }\end{array}$ \\
\hline <userestrict> & Conditions Governing Use & $\begin{array}{l}\text { Condições que afetam o uso do material } \\
\text { depois que o acesso foi concedido. }\end{array}$ \\
\hline$<\mathrm{dsc}>$ & $\begin{array}{l}\text { Description of } \\
\text { Subordinate Components }\end{array}$ & $\begin{array}{l}\text { [Elemento capa que } \\
\text { hierárquica do material.] }\end{array}$ \\
\hline
\end{tabular}

Quadro 1 (continuação) Elementos da tag Achival Description - <archdesc> elements

Fonte: THURMAN, 2005 p.190. Tradução Livre 
Como é possível observar, os elementos presentes na EAD muito se assemelham com as áreas pertencentes às normas ISAD $(G)$ e NOBRADE.

É importante efetuar uma breve explanação dos componentes do elemento de identificação descritiva (DID), pois neste se registra os principais dados da descrição. O elemento DID traz consigo subcampos onde é registrada a representação da informação do material arquivístico. Por este motivo o autor faz uma explanação de cada um dos elementos, que será apresentada no quadro a seguir.

\begin{tabular}{|l|l|l|}
\hline Tags & $\begin{array}{l}\text { Nome dos } \\
\text { Elementos }\end{array}$ & Conteúdo Informacional \\
\hline$<$ abstract $>$ & Abstract & Breve resumo do material para referência rápida. \\
\hline$<$ container $>$ & Container & $\begin{array}{l}\text { Número de identidade da unidade (caixa, pasta) onde } \\
\text { o material está arquivado. }\end{array}$ \\
\hline$<$ origination $>$ & Origination & $\begin{array}{l}\text { Indivíduos ou instituições responsáveis pela criação } \\
\text { do material }\end{array}$ \\
\hline$<$ physdese $>$ & Physical Description & Extensão, dimensão, gênero, formato \\
\hline$<$ physloc $>$ & Physical Location $\_$ & $\begin{array}{l}\text { Local de armazenamento, ex numero prateleira, ou } \\
\text { sala }\end{array}$ \\
\hline$<$ repository $>$ & Repository & $\begin{array}{l}\text { Instituição ou agência responsável pelo acesso } \\
\text { intelectual do material. }\end{array}$ \\
\hline$<$ unitclate $>$ & Date of the Unit & Datas de criação do material \\
\hline$<$ unitid $>$ & ID of the Unit & Identificador único para o material. \\
\hline$<$ unittitle $>$ & Title of the Unit & Nome do Material \\
\hline
\end{tabular}

Quadro 2 Elementos da tag Descriptive Identification - <did> elements

Fonte: THURMAN, 2005 p.191. Tradução Livre

O DID Permite, portanto, a definição de códigos e títulos para a identificação e localização do material, datas limites, nome do produtor e identificação do repositório de custódia.

O campo <origination> não é suficiente para descrever a influência exercida pelo produtor no contexto de produção documental, surge então o uso do padrão EAC para completar os elementos de descrição

A DTD EAC apresenta estrutura semelhantemente ao padrão EAD nas relações hierárquicas existentes em seus elementos. Sua estrutura será apresentada a seguir.

O elemento principal é o Encoded Archival Context <eac>, que acompanha o atributo obrigotório type, que definirá se o produtor é uma corporação ("corpname"), família ("family"), ou uma pessoa("Persname"). Exemplo: <eac type="persname">

Dentro do elemento <eac> encontramos os sub-elementos descritos no quadro a seguir.

\begin{tabular}{|l|l|l|}
\hline Tags & $\begin{array}{l}\text { Nome dos } \\
\text { Elementos }\end{array}$ & Conteúdo Informacional \\
\hline$<$ eacheader $>$ & EAC Header & Criação manutenção e controle da autoridade \\
\hline$<$ condesc $>$ & Context Description & $\begin{array}{l}\text { Descrição da identidade criadora, incluindo nome, e } \\
\text { referências relacionadas aos criadores, recursos, e ou }\end{array}$ \\
\hline
\end{tabular}




\section{Quadro 3 Elementos da etiqueta Encoded Archival Context -<eac> high-level wrapper elements}

Fonte: THURMAN, 2005 p.197. Tradução Livre

É possível observar que o elemento EAC traz consigo os sub-elementos Cabeçalho da EAC e o elemento de Descrição de Contexto

O sub-elemento elemento Cabeçalho da EAC apresenta os elementos listados no quadro a seguir:

\begin{tabular}{|l|l|l|}
\hline Tags & $\begin{array}{l}\text { Nome dos } \\
\text { Elementos }\end{array}$ & Conteúdo Informacional \\
\hline$<$ eacid> & EACldentifier & $\begin{array}{l}\text { Número ou código único de identificação para a } \\
\text { autoridade de registro. }\end{array}$ \\
\hline$<$ mainhist> & Maintenance History & $\begin{array}{l}\text { Ações ou eventos de manutenção envolvendo a } \\
\text { documentação. }\end{array}$ \\
\hline$<$ languagedecl> & $\begin{array}{l}\text { Language } \\
\text { Declaration }\end{array}$ & Linguagens predominantes utilizadas na descrição.. \\
\hline$<$ ruledecl> & Rules Declaration & Padrões de conteúdos usados na descrição. \\
\hline$<$ sourcedecl> & Source Declaration & Fontes utilizadas na descrição \\
\hline$<$ authdecl> & Authority Declaration & Tesauros ou Vocabulários controlados utilizados. \\
\hline
\end{tabular}

Quadro 4 Elementos da tag Encoded Archival Context Header - <eacheader> elements

Fonte: THURMAN, 2005 p.197. Tradução Livre

É possível verificar, portanto, que o elemento Cabeçalho EAD registra a detalhadamente a identificação do produtor, idiomas, e ainda registra as ações praticadas com a documentação do produtor.

O quadro a seguir apresenta os elementos do item Descrição de Contexto:

\begin{tabular}{|l|l|l|}
\hline Tags & Nome dos Elementos & Conteúdo Informacional \\
\hline$<$ identity $>$ & Identity & $\begin{array}{l}\text { Cabeçalhos de nomes autorizados e alternativas } \\
\text { utilizados pelas a entidade. }\end{array}$ \\
\hline$<$ desc $>$ & Description & Descrição formal ou informal da entidade. \\
\hline$<$ eacrels $>$ & EAC Relations & $\begin{array}{l}\text { Uma ou mais relações entre a entidade e outro } \\
\text { corpo coorporativo, pessoa, ou família }\end{array}$ \\
\hline$<$ resourcerels $>$ & Resource Relations & $\begin{array}{l}\text { Uma ou mais relações entre a entidade e um } \\
\text { recurso. }\end{array}$ \\
\hline$<$ funactrels $>$ & $\begin{array}{l}\text { Function or Activity } \\
\text { Relations }\end{array}$ & Um ou mais termos relacionados a entidade. \\
\hline
\end{tabular}

Quadro 5 Elementos da tag condesc - <condesc> elements

Fonte: THURMAN, 2005 p.198. Tradução Livre

Observa-se, ainda, que o elemento Contexto de Descrição descreve as relações mantidas pelo produtor com outras entidades, bem como das funções por ele desenvolvidas. 
Os padrões de Metadados DTD EAC e DTD EAD auxiliam o processo de estruturação de serviços de referência em acervos arquivísticos por meio da web. Uma vez que os metadados de descrição arquivística estejam produzidos de modo padronizado é possível permitir que diferentes sistemas de recuperação da informação os utilizem no processo de localização. Os metadados existentes nos diferentes níveis de descrição poderão contribuir para a construção de poderosos motores de busca para a recuperação da informação orgânica, o que poderá desenvolver a qualidade do serviço de referência em informação orgnânica na web.

A Arquitetura da Informação e os padrões de metadados de representação da informação orgânica oferecem, portanto, recursos respeitáveis para a construção de web sites arquivísticos dinâmicos que possibilitem a mediação da informação orgânica de guarda permanente no meio digital.

\section{CONSIDERAÇÕES FINAIS}

A informação orgânica, gerada no exercício de funções e atividades administrativas e registrada em documentos de arquivo, é apropriada para finalidades distintas durante o ciclo de vida documental. Na fase corrente está voltada aos interesses do administrador e na fase de guarda permanente o foco é direcionado a usuários de grupos distintos com comportamento informacional diferenciado.

A mediação da informação está diretamente vinculada ao serviço de referência, que é responsável por identificar a necessidade de informação do usuário e prover os recursos necessários para satisfazê-la.

Os serviços de referência tornam-se então mais visíveis e buscam o desenvolvimento de instrumentos de pesquisa que auxiliem os usuários a sanarem as necessidades de informação, e são a base fundamental para a atuação do arquivo enquanto instituição.

Nesse ambiente 0 arquivista se destaca na execução do processo descritivo para prover a representação da informação orgânica que possa permitir aos usuários a interação com o acervo arquivístico.

O advento das tecnologias da informação trouxe recursos para que o serviço de referência em arquivos pudesse ser executado a partir da web, o que pouparia o usuário de investimentos desnecessários de recursos de tempo e dinheiro. Em vez de se deslocar ao acervo e consultar catálogos impressos o usuário começa a interagir no ambiente web, indo consultar o acervo físico na certeza de obter êxito na busca por registros documentais pertinentes a sua investigação.

Nesse contexto as linguagens de marcação promovem uma grande estrutura para que 0 arquivista possa desenvolver a representação da informação orgânica registrada no acervo e disponibilizá-la ao usuário. Elas trazem suporte para que a mediação da informação orgânica possa ser realizada por meio de recursos tecnológicos. 
Os padrões de metadados advindos dos serviços de referência unidos aos procedimentos metodológicos da arquitetura da informação possibilitam a criação de sistemas de informação no ambiente web para promover a mediação da informação orgânica presente nos diversos níveis de descrição documental.

Os profissionais da área da Ciência da Informação devem, portanto, se unir aos profissionais da área de Tecnologias da Informação para desenvolver serviços de referência na web.

\section{REFERÊNCIAS}

ALMEIDA JÚNIOR, O. F. Mediação da Informação e Múltiplas Linguagens. Tendências da Pesquisa Brasileira em Ciência da Informação, Brasília, v. 2, n. 1, p. 89-103, jan./ dez. 2009. Disponível em: <http://inseer.ibict.br/ancib/index.php/ tpbci/article/view/17/39>Acesso em 20 dez. 2009.

ANDRADE, R. S. Aspectos introdutórios da representação de informação arquivistica: a Norma Brasileira de Descrição Arquivística (NOBRADE), a Descrição Arquivística Codificada (EAD-DTD) e o projeto Archives Hub. Ponto de Acesso, Salvador, v. 1, n. 2, p. 70-100, jul./ dez. 2007. Disponível em: <http:// www.portalseer.ufba.br/index.php/revistaici/article/view/1589> Acesso em: 01 jan. 2010.

BELLOTO, H. L. Arquivos permanentes: tratamento documental. 4. ed. Rio de Janeiro: FGV, 2006.

Diplomática e tipologia documental em arquivos. 2. ed. Brasília: Briquet de Lemos, 2008.

BUCKLAND, M. K. Information as thing. Journal of the American Society for Information Science, Washington, v. 45, n. 5, p. 351-360, 1991.

CONSELHO INTERNACIONAL DE ARQUIVOS. ISAD (G): Norma Internacional de Descrição Arquivística. 2. ed. Rio de Janeiro: Arquivo Nacional, 2003. Disponível em: <http://www.portalan.arquivonacional.gov.br/Media/ISADG.pdf > Acesso em 01 jan. 2010.

. ISAAR (CPF): norma internacional de registro de autoridade arquivística para entidades coletivas, pessoas e famílias. 2. ed. Rio de Janeiro: Arquivo Nacional, 2004. Disponível em <http://www.portalan.arquivonacional.gov.br/ Media/ISAAR\%20Brasil\%20final.pdf > Acesso em 01 jan. 2010.

CONSELHO NACIONAL DE ARQUIVOS. NOBRADE: Norma Brasileira de Descrição Arquivística. Rio de Janeiro: Arquivo Nacional, 2006.

FERNEDA, E. Recuperação de informação: análise sobre a contribuição da ciência da computação para a ciência da informação. 2003. 388f. Tese (Doutorado em Ciências da Comunicação) - Programa de Pós-Graduação em Ciências da Comunicação, Universidade de São Paulo, São Paulo, 2003. 
FIGUEIREDO, N. R. Serviços de Referência \& Informação. São Paulo: Polis: APB, 1992.

GARCEZ, A. N. R. Fontes Complementares na Pesquisa Historiográfica. In: CASIMIRO, A. P. B. S; LOMBARDI, J. C.; MAGALHÃES, D. R. (Org.). A pesquisa $e$ a preservação de arquivos e fontes para a educação, cultura e memória. Campinas: Alínea, 2009.

GROGAN, D. J. A prática do serviço de referência. Brasília: Briquet de Lemos, 2001.

LE COADIC, Yves-François. A Ciência da Informação. 2. ed. Brasília: Briquet de Lemos, 2004.

MORVILLE, P.; ROSENFELD, L. Information architecture for the world wide web. 3.ed. Sebastopol: O'Really, 2006.

ROUSSEAU Jean-Yves; COUTURE, C. Os Fundamentos da disciplina Arquivística. Lisboa: Dom Quixote, 1998.

SCHELLENBERG, T. R. Arquivos Modernos: Princípios e Técnicas. 6. ed. Rio de Janeiro: FGV, 2006.

THURMAN, A. C. Metadata Standards for Archival Control: An Introduction to EAD and EAC. Cataloging \& Classification Quarterly, New York, v. 40, n. 3/4, p. 183212. 2005.

WILSON, T. D. Human information behavior. Informing Science, v. 3, n. 2, p. 4955, 2000. Disponível em: <http://informationr.net/tdw/publ/papers/2000HIB.pdf.> Acesso em: 22 jun. 2009.

Title

\begin{abstract}
Information Science has for its object of study the general properties of information and analysis of their construction, communication and use processes. Organic information, one of the information types, is the one recorded in the archives, which can be split into two distinct groups based on users: current and permanent, used by administrators, historians/citizens, respectively. After defining the information behavior of each group, the articles directs the discussion to the mediation of information in the permanent archives. The interaction between user and information professionals through references services aiming the user needs is presented. In addition, the standards of archival description and the research instruments as tools to reference service are discussed. Moreover, it argues the importance of information technologies and the new possibilities for the promotion of organic information in permanent archives, especially concerning the information architecture of websites and the conversion of the DTD standards of archival descriptions.
\end{abstract}

\title{
Keywords
}

Archival Records. Information Architecture. Informational Behavior. Archival Description. Markup Languages. Mediation of Information. Reference Service. 


\section{Titulo}

La mediación de la información en los archivos permanentes: servicios de referencia archivística en el ambiente digital

\section{Resumen}

La Ciencia de la Información tiene por objeto el estudio de las propiedades generales de la información y análisis de sus procesos de construcción, comunicación y uso. Entre los tipos informacionales se encuentra la información orgánica, que es registrada en los documentos de archivos. Los usuarios de este tipo de información se pueden dividir en dos grupos distintos por el uso: en la fase actual, por administradores, y en la fase de estado de custodia permanente, por los historiadores y los ciudadanos. Una vez definido el comportamiento de información de cada grupo, la discusión se dirige a la mediación de la información en los archivos permanentes, que presenta la interacción de los usuarios y profesionales de la información a través del servicio de referencia, con el objetivo de satisfacer las necesidades informativas. Presenta las normas de descripción archivística con los instrumentos de trabajo como herramienta de servicio de información en los archivos permanentes. Este texto versa también acerca de las tecnologías de información y nuevas posibilidades para la promoción de la información archivística registrada en el entorno digital con aportes provenientes de la arquitectura de la información de los sitios web, y la conversión a las normas de descripción archivística en DTD.

\section{Palabras clave}

Archivos Permanentes. Servicio de Referencia. Mediación de la Información. Comportamiento Informacional. Descripción Archivística. Lenguaje de Marcado. Arquitectura de la Información.

Recebido em: 21/11/2010

Aceito em: 22/02/2011 